\title{
A study of vascular endothelial growth factor in the cord blood of pre-eclamptics and healthy pregnant women
}

\author{
Anita Rawat ${ }^{1}$, Anil Kumar Gangwar ${ }^{2}$, Archana Ghildiyal ${ }^{3}$, Neena Srivastava ${ }^{4}$, Sunita Tiwari ${ }^{5}$, \\ Uma Singh ${ }^{6}$
}

${ }^{1}$ Assistant Professor, Department of Physiology, Hind Institute of Medical Science, Ataria, Sitapur, ${ }^{2}$ PhD Scholar, ${ }^{3}$ Associate Professor, ${ }^{4,5}$ Professor, Department of Physiology, KGMU, ${ }^{6}$ Professor, Department of Obstetrics and Gynaecology, KGMU, Lucknow, Uttar Pradesh, India

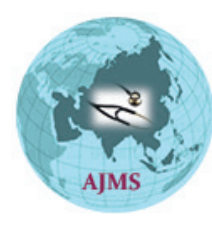

\section{A B S T R A C T}

Background: Pre-eclampsia (PE) is the most frequently encountered medical complication during pregnancy. In developing countries PE is a principal cause of maternal mortality. A disturbance in the angiogenic/antiangiogenic factors and in the hypoxia/placental re-oxygenation process, seems to activate a maternal endothelial dysfunction. Aims and Objective: To estimate Vascular Endothelial Growth Factor (VEGF) level in the cord blood of healthy and Preeclamptic (PEc) pregnant women and to associate this with Preeclamptic pregnancy. Material and Methods: A case-control study ofUmbilical cord serum VEGF levels from women with uncomplicated pregnancies (control group, $n=60$ ) and pregnancies complicated by Pre-eclampsia $(n=40)$. VEGF in the cord serum was estimated by SANDWICH Enzyme Linked Immunosorbent Assay method by using ELISA Kit and then compared between the two groups. Results: The mean VEGF concentrations in the women who had pre-eclampsia (578.62 \pm 468.3 ) were lower than in the control group (625.75 \pm 533.1$)$, but the difference was not statistically significant $(p=0.8548)$. Conclusion: VEGF plays a key role in the instability between endothelial dysfunction and angiogenesis that occurs during Preeclampsia. VEGF levels might be a useful tool for the early diagnosis of Pre-eclampsia.

Access this article online

Website:

http://nepjol.info/index.php/AJMS DOI: 10.3126/ajms.v8i1.15711 E-ISSN: 2091-0576

P-ISSN: 2467-9100

Key words: Vascular endothelial growth factor, Pre-Eclampsia, Cord blood

\section{INTRODUCTION}

Pre-eclampsia (PE), a pregnancy-specific disorder characterized clinically by new onset hypertension and proteinuria after 20 weeks of gestation, is the most frequently encountered medical complication during pregnancy, affecting $\sim 3-5 \%$ of pregnant women worldwide. In developing countries where contact to health care is inadequate, $\mathrm{PE}$ is a principal cause of maternal mortality, with estimates of $>60,000$ maternal deaths/yr. ${ }^{1}$ In the developed world, the load of this disease falls on the neonate because of premature deliveries performed to save the health of the mother. The condition resolves after the delivery of placenta implicating the placenta as a main cause in the pathogenesis of PE. The placental dysfunction, characterized by a disturbance in the angiogenic/antiangiogenic factors and in the hypoxia/placental re-oxygenation process, seems to activate a maternal endothelial dysfunction. It is seen that in PE there are changes in placental development which can compromise the feto-maternal exchange, limiting fetal development, and start a maternal and fetal response to adapt to these changes. ${ }^{2,3}$

In PE, extra-villous cyto-trophoblasts of fetal origin fail to enter the maternal uterine arteries resulting in a defective utero-placental circulation and subsequent placental ischemia. ${ }^{4}$ Placental factors like VEGF, PlGF and sVEGFR-1/ sFlt-1 are then released by the ischemic placenta into the maternal circulation ultimately causing 
generalized endothelial cell dysfunction and multi-organ

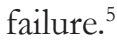

VEGF, a potent angiogenic factor enhances proliferation, migration $^{6}$ and survival of endothelial cells. ${ }^{7}$ It also promotes neovascularization, reduces blood pressure and is vital for the formation and maintenance of the glomerular filtration barrier. ${ }^{8-10}$ Therefore, its deficiency could explain the main clinical manifestations of PE such as hypertension, proteinuria and oedema.

VEGF acts through 2 high affinity tyrosine kinase receptors: VEGFR-1 or /Flt-1 and VEGFR- 2 or KDR. ${ }^{11-13}$ An imbalance in the pro(VEGF)- and anti(VEGFR-1)angiogenic factors in serum is implicated in the pathophysiology of PEc. ${ }^{14}$

This study was designed to see the association of umbilical cord blood (UCB) VEGF level with PEc pregnancies.

\section{MATERIAL AND METHODS}

This case control study was conducted in campus of King George's Medical University, Lucknow, Uttar Pradesh, India. All women gave their informed consent to participate in the study. Ethical clearance was taken from the ethics committee of this university for pursuing the research work. The study group comprised of 80 subjects of 18 to $35 y r s$ age group. Out of 100 subjects, 60 controls (healthy pregnant women) and 40 cases (diagnosed PEc pregnant women as per ACOG guidelines) admitted in Queen Mary Hospital, KGMU were enrolled in our study.

Inclusion criteria were (1) healthy pregnant women (2) Pre-eclamptic women as per ACOG guidelines-

- Blood pressure: $140 \mathrm{~mm} \mathrm{Hg}$ or higher systolic or $90 \mathrm{~mm} \mathrm{Hg}$ or higher diastolic after 20 weeks of gestation in a woman with previously normal blood pressure. Systolic increased $>30 \mathrm{~mm} \mathrm{Hg}$ or diastolic increased $>15 \mathrm{~mm} \mathrm{Hg}$ in a patient with pre-existing chronic hypertension.

- Proteinuria: $0.3 \mathrm{~g}$ or more of protein in a 24-hour urine collection (usually corresponds with $1+$ or greater on a urine dipstick test).

\section{Severe preeclampsia}

- Blood pressure: $160 \mathrm{~mm} \mathrm{Hg}$ or higher systolic or $110 \mathrm{~mm} \mathrm{Hg}$ or higher diastolic on two occasions at least six hours apart in a woman on bed rest.

- Proteinuria: $5 \mathrm{~g}$ or more of protein in a 24 -hour urine collection or $3+$ or greater on urine dipstick testing of two random urine samples collected at least four hours apart.
Exclusion criteria were pregnant women having history of (1) Hypertension (2) Multifetal gestation (3) Diabetes (4) Chronic renal disease (5) Miscarriage (6) Antepartum haemorrhage (7) Platelet disorders (8) Maternal or fetal infection (9) Epilepsy (10) Autoimmune disorders (11) Smoking.

\section{Evaluation}

Complete information about medical history, obstetric history and complications associated with pregnancy were taken in the proforma. All measurements were made by one investigator using standard techniques. Apgar scores at 1 and $5 \mathrm{~min}$ and weight of the newborn were evaluated by the Pediatrician.

\section{Blood pressure}

Hypertension was diagnosed when $2 \mathrm{BP}$ readings of 140/90 $\mathrm{mm} \mathrm{Hg}$ or greater were noted 6 hours apart within a 1 -week period. Blood pressure was measured by using mercury sphygmomanometer with stand. Measuring BP with an appropriate-sized cuff (cuff bladder encircling at least $80 \%$ of arm) placed on the right arm at the same level as the heart is important. The patient must be sitting and ideally, have had a chance to rest for at least 10 minutes before the BP measurement. Korotkoffs sounds (first and fifth phase) were the criteria for systolic and diastolic B.P respectively.

\section{Urine albumin}

Urine albumin was detected by Urine DIPSTICK test in a random midstream sample collected in a clean sterile container.

\section{Blood sample collection and storage}

Five-ml of Umbilical cord blood was collected in a syringe immediately after the delivery of baby from the maternal end of cord. Collected blood in the syringe was allowed to clot at room temperature before being centrifuged at $3000 \mathrm{rpm}$ for 20 minutes. The serum was then stored at -80 degree centigrade until assayed. Cord serum VEGF was measured by SANDWICH Enzyme Linked Immunosorbent Assay method by using AviBion Human VEGF Elisa Kit. This assay employs an antibody specific for human VEGF coated onto a 96- well plate. Standards, samples and biotinylated anti-human VEGF were pipetted into the wells and VEGF present in a sample was captured by the antibody immobilized to the wells and by the biotinylated VEGF- specific detection antibody. After washing away unbound biotinylated antibody, HRP-conjugated steptavidin was pipetted into the wells. The wells were again washed. Following this second wash step, TMB substrate solution was added to the wells, resulting in blue colour development proportional to the amount of VEGF bound. The stop 
solution changed the colour from blue to yellow, and the intensity of the colour is measured at $450 \mathrm{~nm}$. The standard curve was used to determine the amount of VEGF in an unknown sample. The standard curve was generated by plotting the average O.D. $(450 \mathrm{~nm})$ obtained for each of the standard concentrations on the vertical $(\mathrm{Y})$ axis versus the corresponding VEGF concentration $(\mathrm{pg} / \mathrm{ml})$ on the horizontal $(\mathrm{X})$ axis.

Data analysis was performed using Stata 11.2 software (college station, Tx, US). Data were presented as mean \pm standard deviation. Statistical differences between the studied groups were calculated by using the two sample $\mathrm{t}$-test with equal variances, Mann-Whitney test, chi-squared with ties and Kruskal-Wallis test. Correlations between studied parameters were performed using the Spearman's coefficient of correlation. $\mathrm{P}<0.05$ was considered as statistically significant.

\section{RESULTS}

There were no significant differences $(p>0.05)$ in maternal age and gestational age at delivery between the PEc and control groups. Compared with normal pregnancy, PEc pregnancy presented significantly higher systolic and diastolic blood pressure $(p<0.001)$. LSCS was significantly increased in PEc group ( $\mathrm{p}=0.003)$ as compared to control group (Table 1).

Both the groups were almost similar in their neonatal characteristics like infant weight, sex and apgar score at 1 min and 5 mins, showing no significant difference ( $p>0.05)$ (Table 2).

The mean VEGF concentrations in the women who had pre-eclampsia $(578.62 \pm 468.3)$ were lower than in the control group (625.75 \pm 533.1 ), but the difference was not statistically significant $(\mathrm{p}=0.8548)$ (Table 3$)$.

\section{DISCUSSION}

In present study the mean cord serum VEGF levels were lower in pregnant women having Pre-eclampsia, but the difference was statistically insignificant. Our results corroborate with findings of a study which also observed that the difference in the Levels of VEGF in UCB samples between the two groups was not significant. ${ }^{15}$ Some studies observed that umbilical cord plasma free VEGF were significantly decreased in PE compared to the control group. ${ }^{16,17}$ On the other side there are studies which are not in accordance with the present study. These studies found that the cord serum VEGF levels were significantly higher in PEc group as compared to control group. ${ }^{18-20}$
In the pathophysiology of PE an imbalance in the pro- and anti-angiogenic factors in serum is involved. Therefore, a combined analysis of the circulating pro- and antiangiogenic factors would be more useful in patients with PE. In the present study we only measured the level of cord serum VEGF and the estimation of level of sVEGFR-1 in the cord serum was not done. The duration of study and the sample size were inadequate to achieve confirmatory results.

VEGF is regulated by alterations in oxygen pressure and by VEGFR-1, as its antagonist. ${ }^{21}$ VEGF production is up-regulated by low oxygen tension. ${ }^{22}$

There are several studies carried out in maternal serum associating VEGF with PE which demonstrated that serum sVEGFR-1 levels were significantly elevated in PE women compared with controls. The placental sFlt1, an antagonist of VEGF is up-regulated in PE, leading to increased systemic levels of sFlt1. Increased circulating sFlt1 in patients with PE is associated with decreased circulating levels of free VEGF. The balance

\begin{tabular}{|c|c|c|c|}
\hline Variables & Control $(n=60)$ & PEc $(n=40)$ & $\mathrm{p}$-value \\
\hline Age (years) & $25.65 \pm 3.4$ & $24.73 \pm 4.0$ & $0.2212^{*}$ \\
\hline $\begin{array}{l}\text { Gestational } \\
\text { Age (weeks) }\end{array}$ & $38.33 \pm 2.1$ & $37.51 \pm 3.0$ & $0.5056^{* *}$ \\
\hline $\begin{array}{l}\text { Systolic BP } \\
(\mathrm{mmHg})\end{array}$ & $122.10 \pm 6.8$ & $147.80 \pm 11.0$ & $0.000^{* *}$ \\
\hline $\begin{array}{l}\text { Diastolic BP } \\
(\mathrm{mmHg})\end{array}$ & $78.07 \pm 4.2$ & $95.40 \pm 7.5$ & $0.000^{* *}$ \\
\hline Normal delivery & $88.33 \%$ & $62.50 \%$ & $0.003^{\#}$ \\
\hline LSCS & $11.67 \%$ & $37.50 \%$ & $0.003^{\#}$ \\
\hline
\end{tabular}

\begin{tabular}{|c|c|c|c|}
\hline Variables & Normal $(n=60)$ & $\operatorname{PEc}(n=40)$ & P-value \\
\hline Weight (kg) & $2.80 \pm 0.5$ & $2.73 \pm 0.5$ & $0.4564^{*}$ \\
\hline Male & $56.67 \%(34)$ & $55.00 \%(22)$ & $1.000^{\star *}$ \\
\hline Female & $43.33 \%(26)$ & $45.00 \%(18)$ & $1.000^{* *}$ \\
\hline \multicolumn{4}{|l|}{ Apgar Score } \\
\hline 1 minute & $6.16 \pm 0.6$ & $6.16 \pm 0.4$ & $0.8585^{* * *}$ \\
\hline 5 minute & $7.09 \pm 0.4$ & $7.16 \pm 0.4$ & $0.4221^{*}$ \\
\hline
\end{tabular}

\begin{tabular}{|c|c|c|c|}
\hline Variable & $\begin{array}{c}\text { Study Group } \\
(n=60)\end{array}$ & $\begin{array}{c}\text { Control Group } \\
(n=40)\end{array}$ & $P$ value \\
\hline VEGF (pg/ml) & $578.62 \pm 468.3$ & $625.75 \pm 533.1$ & 0.8548 \\
\hline
\end{tabular}


between VEGF, PlGF, and their receptors is important for effective placental development during pregnancy and hypoxia mediated increase in levels of sVEGFR-1 may lead to dys-regulated angiogenesis associated with PE. ${ }^{23-30}$ The probable explanation for our finding is that in PE trophoblasts under hypoxic conditions seem to increase sVEGFR-1 production, an antagonist of VEGF.

Although we have not measured the level of sVEGFR-1 in the cord serum in our study but previous studies have demonstrated and confirmed this finding. ${ }^{17}$ VEGF presented reduced values in new-borns from PEc pregnancies, as compared with normal cases as the main target for sVEGFR-1 (significantly higher in UCB circulation in PE cases) is probably VEGF, explaining the observed reduction in UCB when compared to the normal value. Our data suggest that in PE, in UCB circulation, a close interaction seems to exist between endothelial dysfunction and angiogenesis disturbance, and that VEGF seems to play a central role in these disturbances. To conclude our data suggest that in PE, in UCB circulation, a close interaction seems to exist between endothelial dysfunction and angiogenesis disturbance, and that VEGF seems to play a central role in these disturbances. Further studies are needed to find out whether VEGF levels might be a useful tool for the early diagnosis of Pre-eclampsia. The present study is one of ongoing step in the direction of establishing role of VEGF in pathophysiology of Preeclampsia. However to achieve more confirmatory results further studies on larger sample size are needed.

\section{REFERENCES}

1. World Health Organization. World Health Report: Make Every Mother, and Child Count. Geneva. 2005.

2. Pijnenborg R, Vercruysse $L$ and Hanssens $M$. The uterine spiral arteries in human pregnancy: facts and controversies. Placenta 2006; 27(9-10): 939-958.

3. Young $B$, Levine $R$ and Karumanchi A. Pathogenesis of preeclampsia. Annu Rev Pathol 2010; 5: 173-192.

4. Brosens IA, Robertson WB and Dixon HG. The role of the spiral arteries in the pathogenesis of preeclampsia. Obstet Gynecol Annu 1972; 1: 177-191.

5. Lee ES, Oh MJ, Jung JW, Lim JE, Seol HJ, Lee KJ, et al. The levels of circulating vascular endothelial growth factor and soluble Flt-1 in pregnancies complicated by preeclampsia. J Korean Med Sci 2007; 22(1): 94-98.

6. Ferrara N, Gerber HP and LeCouter J. The biology of VEGF and its receptors. Nat Med 2003; 9(6): 669-676.

7. Gerber HP, McMurtrey A, Kowalski J, Yan M, Keyt BA, Dixit V, et al. Vascular endothelial growth factor regulates endothelial cell survival through the phosphatidylinositol 3'-kinase/Akt signal transduction pathway. Requirement for Flk-1/KDR activation. J Biol Chem 1998; 273(46): 30336-30343.
8. Ferrara $\mathrm{N}$ and Gerber HP. The role of vascular endothelial growth factor in angiogenesis. Acta Haematol 2001; 106: 148-156.

9. Neufeld G, Cohen T, Gengrinovitch S and Poltorak Z. Vascular endothelial growth factor (VEGF) and its receptors. FASEB $J$ 1999; 13(1): 9-22.

10. Eremina V, Sood M, Haigh J, Nagy A, Lajoie G, Ferrara N, et al. Glomerular-specific alterations of VEGF-A expression lead to distinct congenital and acquired renal diseases. J Clin Invest 2003; 111(5): 707-716.

11. Jelkmann W. Pitfalls in the measurement of circulating vascular endothelial growth factor. Clin Chem 2001; 47(4): 617-623.

12. Sugimoto $H$, Hamano $Y$, Charytan $D$, Cosgrove $D$, Kieran $M$, Sudhakar A, et al. Neutralization of circulating vascular endothelial growth factor (VEGF) by anti- VEGF antibodies and soluble VEGF receptor 1 (sFlt-1) induces proteinuria. J Biol Chem 2003; 278(15): 12605-12608.

13. Ferrara N, Houck K, Jakeman L and Leung DW. Molecular and biological properties of the vascular endothelial growth factor family of proteins. Endocr Rev 1992; 13(1): 18-32.

14. Romero R, Nien JK, Espinoza J, Todem D, Fu W, Chung H, et al. A longitudinal study of angiogenic (placental growth factor) and anti-angiogenic (soluble endoglin and soluble vascular endothelial growth factor receptor-1) factors in normal pregnancy and patients destined to develop preeclampsia and deliver a small for gestational age neonate. J Matern Fetal Neonatal Med 2008; 21(1): 9-23.

15. Baker PN, Krasnow J, Roberts JM and Yeo KT. Elevated serum levels of vascular endothelial growth factor in patients with preeclampsia. Obstet Gynecol 1995; 86(5): 815-821.

16. Kwon JY, Maeng YS, Kwon YG, Kim YH, Kang MH and Park YW. Decreased endothelial progenitor cells in umbilical cord blood in severe preeclampsia. Gynecol Obstet Invest 2007; 64(2): 103-108.

17. Cristina Catarinoab, Irene Rebeloab, Luís Belo ab, Susana Rocha ab, Elisabeth B, Castro ab, et al. Fetal and maternal angiogenic/ anti-angiogenic factors in normal and preeclamptic pregnancy. Growth Factors 2009; 27(6): 345-351.

18. Galazios G, Papazoglou D, Giagloglou K, Vassaras G, Koutlaki N and Maltezos E. Umbilical cord serum vascular endothelial growth factor (VEGF) levels in normal pregnancies and in pregnancies complicated by preterm delivery or pre-eclampsia. Int J Gynaecol Obstet 2004; 85: 6-11.

19. Laskowska M, Laskowaska K, Leszczynska-Gorzelak B and Oleszczuk J. Are the maternal and umbilical VEGF-A and SVEGF-R1 altered in pregnancies complicated by preeclampsia with or without intrauterine foetal growth retardation? Preliminary communication. Med Wieku Rozwoj 2008; 12(1): 499-506.

20. Kulkarni AV, Mehendale SS, Yadav HR, Kilari AS, Taralekar VS and Joshi SR. Circulating angiogenic factors and their association with birth outcomes in preeclampsia. Hypertens Res 2010; 33(6): 561-567.

21. Nagamatsu T, Fujii T, Kusumi M, Zou L, Yamashita T, Osuga $Y$, et al. Cytotrophoblasts up-regulate soluble fms-like tyrosine kinase-1 expression under reduced oxygen: an implication for the placental vascular development and the pathophysiology of preeclampsia. Endocrinology 2004; 145(11): 4838-4845.

22. Li H, Zhang $Y$, Lewis $D$ and Wang $Y$. Hypoxia-induced increase in soluble Flt1 production correlates with enhanced oxidative stress in throphoblast cells from the human placenta. Placenta 2005; 26(2-3): 210-217.

23. Polliotti BM, Fry AG, Saller DN, Mooney RA, Cox C and Miller RK. Second-trimester maternal serum placental growth factor and vascular endothelial growth factor for predicting severe, earlyonset preeclampsia. Obstet Gynecol 2003; 101(6): 1266-1274. 
24. Koga K, Osuga Y, Yoshino O, Hirota Y and Ruimeng X. Elevated serum soluble vascular endothelial growth factor receptor 1 (s VEGFR-1) levels in women with preeclampsia. J Clin Endocrinol Metab 2003; 88(5): 2348-2351.

25. Maynard SE, Min JY, Merchan J, Lim KH, Li J, Mondal S, et al. Excess placental soluble fms-like tyrosine kinase 1 (sFlt1) may contribute to endothelial dysfunction, hypertension, and proteinuria in preeclampsia. J Clin Invest 2003; 111(5): 649-658.

26. Tsatsaris V, Goffin F, Munaut C, Franc J, Brichant O, Pignon MR, et al. Over expression of the soluble vascular endothelial growth factor receptor in preeclamptic patients: Pathophysiological consequences. J Clin Endocrinol Metab 2003; 88(11): 5555-5563.
27. Levine RJ, Maynard SE, Qian C, Lim KH, England LJ, Yu KF, et al. Circulating angiogenic factors and the risk of preeclampsia. N Engl J Med 2004; 350(7): 672-683.

28. Ahmad $S$ and Ahmed A. Antiangiogenic effect of soluble vascular endothelial growth factor receptor-1 in placental angiogenesis. Endothelium 2005; 12: 89-95.

29. Wang A, Rana S and Karumanchi A. Preeclampsia: The role of angiogenic factors in its pathogenesis. Physiology 2009; 24(3): 147-158.

30. Varughese B, Bhatla N, Kumar R, Dwivedi SN and Dhingra R. Circulating angiogenic factors in pregnancies complicated by pre-eclampsia. Natl Med J India 2010; 23(2): 77-81.

\section{Authors Contribution:}

AR - Concept and design of the study, reviewed the literature, manuscript preparation and critical revision of the manuscript; AKG - Collected data and review of literature and helped in preparing first draft of manuscript; AG - Concept and design of the study, reviewed the literature; NS - Concept and design of the study, manuscript preparation and critical revision of the manuscript; ST - Conceptualized study, prepared first draft of manuscript and critical of the manuscript; US - Concept, collected data and review of literature and helped in preparing first draft of manuscript.

Source of Support: Nil, Conflict of Interest: None declared. 